\title{
latrogenic Ureteral Injury During Incisional Hernia Repair in a Kidney Recipient
}

\author{
Mutlu Unver ${ }^{\mathrm{a}, \mathrm{c}}$, Ozgur Firat ${ }^{\mathrm{b}}$, Taylan Ozgur Sezer ${ }^{\mathrm{b}}$, \\ Cuneyt Hoscoskun ${ }^{\mathrm{b}}$
}

\begin{abstract}
Incisional hernia is not a rare complication in kidney allograft recipients, due to prolonged dialysis, immunosuppressive drugs, especially, corticosteroids, and high prevalence of diabetes mellitus. Although the use of immunosuppressive drugs increases the risk of infection with synthetic materials, using mesh to prevent hernia recurrence in patients with multiple predisposing factors is safe and necessary. Repeated surgeries cause pathological distortion of anatomy which prevents the intraoperative visibility of the ureter and increases the risk of injury. In the present case, we report a very rare ureteric injury in a patient who underwent incisional hernia repair with propylene mesh after renal transplantation.
\end{abstract}

Keywords: Ureteral injury; Incisional hernia; Kidney recipient; Mesh

\section{Introduction}

Incisional hernia is a well-known complication after abdominal surgery. Although the incidence of incisional hernia after renal transplantation is unclear, it is not a rare complication in kidney allograft recipients, due to prolonged dialysis, immunosuppressive drugs, especially, corticosteroids, and high prevalence of diabetes mellitus. Incisional hernia after kidney transplantation increases patient morbidity and affects the quality of life. Although the use of immunosuppressive drugs increases the risk of infection with synthetic materials, using mesh to prevent hernia recurrence in patients with multiple predisposing factors is safe and necessary [1]. Iatrogenic ureteral injury is a potential complication in various surgical procedures [2]. The incidence of such complications varies between $0.5 \%$ and $10 \%[3,4]$. The risk of injury is related to the sophistication

Manuscript accepted for publication November 23, 2016

aDepartment of General Surgery, Izmir Medicalpark Hospital, Izmir, Turkey ${ }^{b}$ Division of Organ Transplantation, Department of General Surgery, Ege Univercity, Izmir, Turkey

${ }^{c}$ Corresponding Author: Mutlu Unver, Department of General Surgery, Izmir Univercity, Izmir, Turkey. Email: mutluunver@gmail.com

doi: https://doi.org/10.14740/jcs310w of the procedure or presence of periureteric pathology. The prevalent presentation in ureteral injury is flank pain, fever or leukocytosis. About $10 \%$ of patients have hematuria following surgical injury. Anuria may result from bilateral ureteric injury or from unilateral ureteric injury in a solitary functioning kidney. Herein, we present a case of unusual ureteric injury in a patient who underwent incisional hernia repair with propylene mesh after renal transplantation.

\section{Case Report}

A 29-year-old male patient underwent living donor renal transplantation due to focal segmental glomerulosclerosis in 2006. On the postoperative period, the patient underwent an emercency surgery for uretero-neo-cystostomy necrosis and revision of uretero-neo-cystostomy was performed 7 days after the renal transplantation. Following an uneventful recovery, the patient was discharged 10 days after the second operation. His maintenance immunosuppression included tacrolimus, mycophenolate mofetil and prednisone. The patient presented with incisional hernia 3 years after the renal transplantation. We decided to repair hernia using propylene mesh due to the large size of hernia $(8 \mathrm{~cm})$. We approximated the fascial edges and placed the mesh on fascia. Before closure of the wound, a hemovac drain was inserted over the mesh. During the postoperative period, the urine of the patient began to decrease and subsequently developed a clear discharge from the hemovac drain which was consistent with urine on biochemical analysis. We performed Tc99m DTPA dynamic renal scintigraphy to detect the site of the urinary leakage. Tc99m DTPA dynamic renal scintigraphy showed distal ureteric leakage. In the exploratory laparotomy, we found the partial distal ureteric injury (Fig. 1a) and confirmed the diagnosis as iatrogenic ureteral injury. The patient underwent primary repair of the injury and insertion of a JJ stent (Fig. 1b). He was discharged from clinic 2 weeks later and the stent was removed 4 weeks later. After a 30-month follow-up, he remains in good health without any complication and recurrence of hernia.

\section{Discussion}

The incidence of incisional hernia is between $3 \%$ and $13 \%$ 


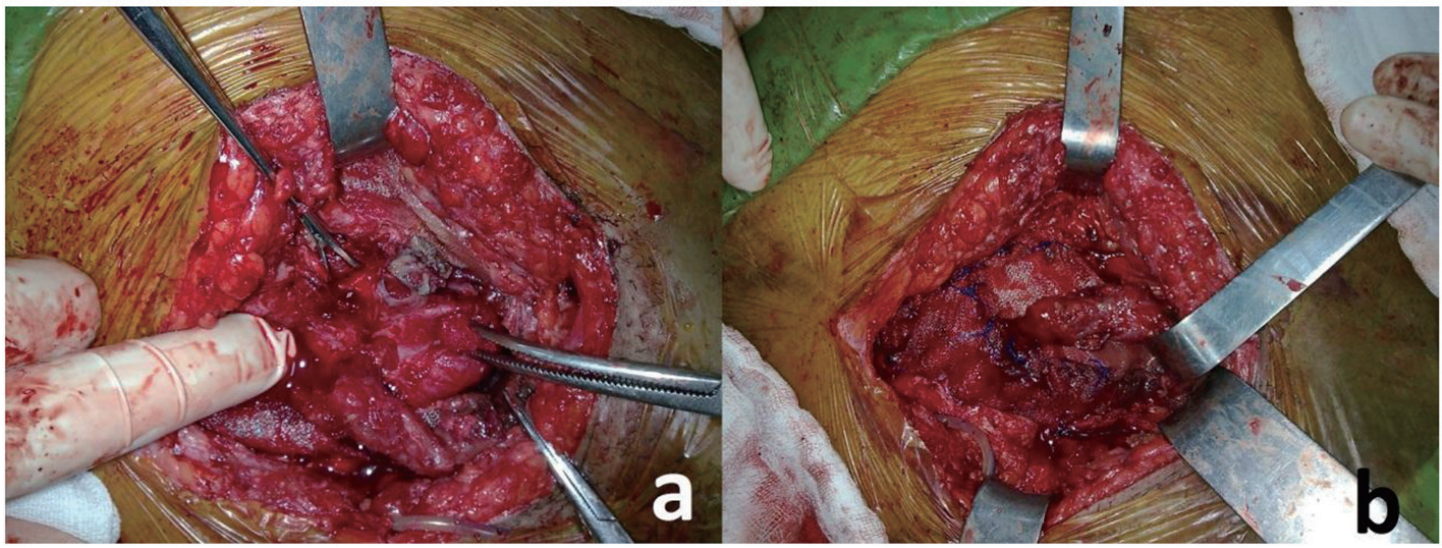

Figure 1. (a) Partial ureteral injury. (b) Final position after primary repair.

$[5,6]$. The predisposing factors for incisional hernia are age, obesity, alcoholism, smoking, emergency surgeries, wound infection, hematoma, technical error, and unsuitable suture material. In patients with chronic renal failure, who have undergone kidney transplantation, multiple factors interfere with wound healing, such as long-term uremia, malnutrition before renal transplantation, and administration of corticosteroids and azathioprine, postoperatively [1]. Varga et al stated that the ratio of incisional hernia in renal transplantations is $2.6 \%$ [7]. In the present case, incisional hernia developed 3 years after the renal transplantation. But it was stated that incisional hernia occurs in up to $70 \%$ of the patients in the first postoperative year. Only in 10\% it develops between 1 and 5 years after transplantation $[1,8]$. Complications such as hematoma, lymphocele, urinary fistula and repeated surgeries after renal transplantations are the predisposing factors for incisional hernia [1]. Repeated surgery for ureteral leakage could be the possible predisposing factor in the present case. The ureter can be damaged anywhere along its course but the frequency of injury increases in the distal segment [9]. Pathological distortion of anatomy prevents the intraoperative visibility of the ureter and increases the risk of injury. In the present case, inflammatory response, connective tissue proliferation and fibrosis formation against the repeated surgeries and propylene mesh were the reasons for anatomical distortion. There are too many treatment options for iatrogenic ureteric injuries. Urinary diversion, end to end anastomosis, primary repair, ureteric stenting, appendix interposition and autotransplantation are the treatment options stated in the literature $[10,11]$. The ureteric injury was partial, so we performed primary repair with JJ stenting in this case. The rate of the complications after the injury repair is not known. Urinoma, abscess and peritonitis are the short-term complications. Ureteral stricture and retained stent leading to stone formation are recognized long-term complications from such procedures [12]. The transplanted ureter is commonly placed on the ventral side and native ureter is placed on the posterior side. The abnormal localization of the ureter in kidney recipients, fibrosis formation against the repeated surgeries and previous surgical complications are associated with high risk of ureteral injury, so a high index of suspicion is warranted during incisional hernia repair in kidney recipients.

\section{Author Contributions}

Mutlu Unver, MD: manuscript conception and design, acquisition of data and drafting of manuscript. Ozgur Firat, PhD, MD: manuscript conception and design, acquisition of data and drafting of manuscript. Taylan Ozgur Sezer, MD: manuscript conception and design, acquisition of data. Cuneyt Hoscoskun, PhD, MD: manuscript conception and design, revision of the manuscript.

\section{References}

1. Mahdavi R, Mehrabi M. Incisional hernia after renal transplantation and its repair with propylene mesh. Urol J. 2004;1(4):259-262.

2. Giberti C, Germinale F, Lillo M, Bottino P, Simonato A, Carmignani G. Obstetric and gynaecological ureteric injuries: treatment and results. Br J Urol. 1996;77(1):21-26.

3. Bright TC, 3rd, Peters PC. Ureteral injuries secondary to operative procedures. Report of 24 cases. Urology. 1977;9(1):22-26.

4. Neuman M, Eidelman A, Langer R, Golan A, Bukovsky I, Caspi E. Iatrogenic injuries to the ureter during gynecologic and obstetric operations. Surg Gynecol Obstet. 1991;173(4):268-272.

5. Eubanks WS. Hernias. In: Townsend CM, Mattox KL, Evers BM. Sabiston text book of surgery. 16th ed. Philadelphia: WB Saunders; 2001. p. 783-801.

6. Wants GE. Abdominal wall hernias. In: Shwartz SI, Shires GT, Spencer FC, Daly JM, Fischer JE, Galloway AC, editors. Principles of surgery. 7th ed. McGraw Hill; 1999. p. 1585-1611.

7. Varga M, Matia I, Kucera M, Oliverius M, Adamec M. Polypropylene mesh repair of incisional hernia after kidney transplantation: single-center experience and review of the literature. Ann Transplant. 2011;16(3):121-125.

8. Morris PJ. Azathioprine and steroids. In: Morris PJ, editor. Kidney transplantation principles and practice. 5th 
ed. WB Saunders; 2001. p. 217-226.

9. Preston JM. Iatrogenic ureteric injury: common medicolegal pitfalls. BJU Int. 2000;86(3):313-317.

10. Meng MV, Freise CE, Stoller ML. Expanded experience with laparoscopic nephrectomy and autotransplantation for severe ureteral injury. J Urol. 2003;169(4):1363-1367.
11. Baykal K, Onol Y, Albayrak S, Inal H, Senkul T. Ureteral injury during appendectomy. Int Urol Nephrol. 1996;28(5):709-711.

12. Elliott SP, McAninch JW. Ureteral injuries from external violence: the 25-year experience at San Francisco General Hospital. J Urol. 2003;170(4 Pt 1):1213-1216. 